\title{
A Follow-up Study into Different Ways of Experiencing Leisure
}

\author{
Michael Watkins, Griffith University, Brisbane, Queensland
}

\begin{abstract}
Phenomenographic research reveals that leisure studies students can experience the meaning of leisure as passing time, exercising choice, escaping pressure, and achieving fulfilment; and that these meanings can be operationalised as a continuum of developmentally ordered understandings. This study sought to clarify the nature and order of meanings using follow-up research with the same leisure studies students $(n=33)$ and a group of non-leisure studies students ( $n=23$ ). Results indicated initial descriptions of meanings were reasonably accurate and that both groups of students expressed similar content in meanings. Development in understanding leisure was supported by findings that showed progression from passing time, to exercising choice, to escaping pressure, to achieving fulfilment was positively related to increasing age and more diverse life experiences.
\end{abstract}

\section{Introduction}

An ongoing challenge for leisure researchers concerns the need to clarify the nature of leisure meanings. Watkins and Bond (2007) addressed this challenge using a research approach called phenomenography to map difference in leisure meanings for students in a three-year Australian leisure studies undergraduate program. Interviews with students identified four categories of meaning: passing time, exercising choice, escaping pressure, and achieving fulfilment. While other researchers have used the same or similar labels to categorise leisure meanings, elaborating how individuals experience these meanings has been infrequently considered. In contrast, Watkins and Bond showed each meaning was composed of several aspects forming a particular way of experiencing leisure, and that these aspects could be conceptualised as dimensions of variation capturing different relational values in the contexts, intentions, temporality, emotions, and outcomes of meanings. Penetrating category labels to reveal the underlying dimensional structure and relational qualities of meanings was subsequently argued to contribute an additional 
approach to researching meanings by emphasising critical variations in experiences of leisure.

A further contribution of the study operationalised the four meanings as a continuum of developmentally ordered understandings. This was achieved by comparing meanings and using interpretive judgements to argue some meanings were more complex understandings than other meanings because they demonstrated greater diversity in the relational values of dimensions, more flexibility in the arrangement of dimensions in awareness of leisure, higher levels of integration between leisure and other aspects of life, and increasing inclusivity in the overall meaning of leisure. Based on these judgements, the order of meanings from less to more complex understandings was proposed to be passing time, exercising choice, escaping pressure, and achieving fulfilment.

Procedures used to enhance the trustworthiness of these results included employing a team of three researchers, using whole-interview transcripts as the unit of analysis to maintain their contextual integrity, having researchers conduct independent preliminary analyses of interviews, and using peer debriefing whereby a final set of results was presented and defended with reference to the interview data. A final procedure involved two independent colleagues performing an inter-judge reliability assessment of the findings. An additional source of reliability came from a psychometric study in which the four meanings were used to develop a 23-item scale called the Leisure Meanings Inventory (Shultz \& Watkins, 2007). Testing the scale with 475 residents from a metropolitan city showed subjects from diverse backgrounds were capable of discerning among the four meanings, with the instrument measuring a modest but acceptable $54.2 \%$ of explained variance.

However, as noted by Watkins and Bond (2007), their findings formed part of a longitudinal project investigating change in meanings over eight years. This project consisted of four interviews conducted with students at the beginning of their first year of study, at the end of second and third years of study, and then five years after graduation. Thus, while the results described above represent an initial set of findings, three subsequent rounds of interviews reported in the present paper provided an opportunity to gather additional evidence about the meanings, dimensions, and order of complexity in understanding leisure.

A further opportunity to clarify the findings came from a study of nonleisure studies students enrolled at the same university as the leisure studies students. While the principal aim was to study difference in meanings by theoretically sampling students from a broader range of backgrounds, the study was also informed by an issue raised by Weissinger, Caldwell and Mobily 
(1992) concerning the use of leisure studies students to research leisure topics. These scholars hypothesised that leisure studies students may differ from non-leisure studies students on self-reported leisure variables due to selection biases (i.e., particular types of students may be attracted to leisure studies courses) or because students' knowledge of leisure may be positively influenced by exposure to courses designed to develop their understandings of leisure. This hypothesis was subsequently tested by administering attitudinal and behavioural measures of leisure to students in leisure studies and nonleisure studies courses. Findings revealed leisure studies students reported lower levels of leisure boredom and higher levels of leisure motivation and ethics compared with their non-leisure studies counterparts. No difference was reported for scores of leisure satisfaction or participation. As noted by the researchers, these results neither confirm nor disconfirm possible reasons for these differences; but they justify the need to test evidence from leisure studies students against evidence from non-leisure studies students.

Two additional features of the Watkins and Bond (2007) study are worth noting. First, the study reported information about leisure meanings using qualitative descriptions and interpretations and neglected information about their quantitative features. Describing the distribution of meanings and their possible relationship with students' personal characteristics, therefore presents an opportunity to extend the initial study. The second feature relates to the first, in that quantitative relationships may support the proposed order of students' experiences. A concern arose related to the positioning of exercising choice as a less complex understanding of leisure compared with escaping pressure. If experiences of leisure reflect individuals' developmental stages suggested by life-span theories (Henderson, Bialeschki, Shaw, \& Freysinger, 1999; Kleiber, 1999; Osgood \& Howe, 1984) or the growth of cognitive understandings postulated by epistemological theories (see Hofer $\&$ Pintrich, 1997), then different experiences should logically relate to developmental indicators exhibited by students (e.g., their age and life experience characteristics). Should this be so, then it may support the proposed order of understanding and further illustrate the developmental nature of leisure meanings.

This study, therefore, represents an attempt to clarify the initial study results with a follow-up investigation and to better specify the nature and order of leisure meanings before reporting a longitudinal study concerning change in meanings in a forthcoming paper (Watkins, in preparation). Questions guiding the present study were: (1) would additional data identify the same or, alternatively, new leisure meanings and dimensions, (2) would leisure studies and non-leisure studies students differ in their meanings, and 
(3) would the order of complexity in understanding leisure be supported by positive relationships between meanings and students' age and life experience characteristics.

\section{Method}

Study design

The design of the initial study was informed by phenomenography (Marton \& Booth, 1997; Watkins, 2000). A key principle of phenomenographic research is that it claims to adopt a subject-centred approach by studying variation in subjects' experiences of phenomena without recourse to a priori theoretical or empirical knowledge imposed on subjects through procedures for collecting and analysing data. Although this principle was used in the follow-up study during data collection, it was not maintained during data analysis. This was because a decision was made to use the four meanings and dimensions of variations as the framework for analysing students' interviews and assessing whether data contained in interviews supported the initial results. Marton (1986: 34) provides a justification for this approach by arguing that phenomenographic results derived from one set of data, 'though originating from a contextual understanding, are decontextualised and hence may prove useful in contexts other than the one being studied.'

The follow-up study more accurately represents a form of triangulation research outlined by Denzin (1978). According to Denzin, improving the credibility of research findings can be achieved using multiple and different sources of data. In the present study, multiple sources of data were the three additional interviews collected from leisure studies students, with the different source of data being provided from single interviews undertaken with the non-leisure studies students. The design used in the present study is therefore purposefully hermeneutical in nature, building on previous understandings in an iterative and cumulative manner rather than establishing reliability through criteria of independence and objectivity favoured in positivist research.

\section{Study sample}

Leisure studies students were selected for the initial study from a population of first-year undergraduate leisure studies majors using a proportionate random sampling procedure. This procedure resulted in a sample of $35 \mathrm{stu}-$ dents from a population of 97 students. Two tapes were found to be defective during transcription and, thus, 33 useable interviews were obtained from the first round of data collection. The 35 students formed the sample for three subsequent interviews rounds, resulting in 24 useable interviews in Year 2, 
14 in Year 3 and 27 in Year 8. Although retention of students varied between years, the overall retention rate between the first and the eighth year was $82 \%$.

The sample of leisure studies students in first year consisted of 15 females and 18 males, with an average age of 20.9 years (range $=17-38$ years). Most were from Anglo-Australian and middle-class backgrounds, 2 were Aboriginal Australians and 2 were international students; 1 from Hong Kong and the other from Vietnam. Students' career interests focused on community and outdoor recreation, sport, and tourism. As students progressed through the project the proportion with different sample characteristics remained reasonably consistent.

Non-leisure studies students were selected using a convenience sampling method. Teaching staff responsible for various academic programs were asked for permission to invite students to participate in the study. Of the 23 students who accepted, 15 were female and 8 were male. The age of students ranged between 17 to 40 years, with an average age of 22.3 years. The sample was predominantly Anglo-Australian in nationality $(n=15)$, but included 4 Aboriginal Australians, and 4 international students; 3 from northern Europe and 1 from Hong Kong. Twenty students were enrolled in undergraduate courses; 6 in Year 1, 15 in Year 2, and 2 in Year 3; and 3 in postgraduate research courses. Students' fields of study were the performing arts $(n=7)$, humanities $(n=5)$, technical education teaching $(n=4)$, environmental science $(n=3)$, psychology/criminal justice $(n=2)$, and primary education teaching $(n=2)$.

\section{Data collection}

Data collection consisted of interviews between a researcher and a student. Interviews with the leisure studies students were conducted by three researchers in Years 2 and 3, and then by the author of the present study in Year 8. The same researcher conducted interviews with the non-leisure studies sample in the second year of data collection for the leisure studies students. The data set consisted of 65 interview transcripts collected from leisure students and 23 transcripts from non-leisure students.

Interviews followed an open-ended conversational format that required students to provide several different examples of leisure. These examples were probed to reveal underlying meanings and expanded using clarifying and paraphrasing questions to check the researcher's understandings of student responses (see Watkins \& Bond, 2007). Information about student characteristics (e.g., gender, age, nationality, program entry mode, and life experience) came from background material in student interviews and university records. 


\section{Data analysis}

Analysis of leisure meanings was undertaken by reading interview transcripts for both groups of students with reference to the four categories of meanings and dimensions obtained from the initial study, highlighting responses (e.g., words and phrases) to questions about leisure, coding responses as indicators of a particular experience in the margins of transcripts, and then coding the whole transcript as being indicative of one or more categories. Transcripts with the same codes were grouped to permit within-category and betweencategory comparison checks.

Descriptive methods analysing relationships among meanings involved two procedures. The first consisted of allocating students' transcripts to a particular category and then counting the number of students in each category. Frequencies and percentages report the results of this procedure for the combined group of students and for each sample. The second procedure used student characteristics to create profiles of students contributing to each category. These characteristics were reported in quantitative form along with narrative descriptions for each category.

Prior to undertaking the descriptive analysis, a decision had to be made about the basis for allocating students to a particular category. An outcome of the coding process described above, revealed individual transcripts contained aspects of different experiences, enough aspects to indicate a complete meaning or in some cases enough aspects to indicate two complete meanings. Using an approach adopted by Marton, Dall'Alba and Beaty (1993), a decision was made to allocate students to the highest or most complex understanding of leisure interpreted from the initial study.

\section{Results and discussion}

Results are presented and briefly discussed in four sections: clarification of the leisure meanings, clarification of the dimensions of variation, the distribution of meanings, and differences between leisure studies and non-leisure studies students' meanings, and support for the developmental order of understanding leisure. In the first two sections, references are made to the non-leisure studies students' experiences to illustrate evidence about their meanings and dimensions of leisure.

\section{Clarification of the leisure meanings}

Leisure as passing time (A) In the initial study, the meaning of passing time was experienced as filling spare time when there was nothing more important to do. Students related their experience to the context of having unoccupied and discrete blocks of time, to the intention of needing to fill time, to 
understanding time as being spare or left over, to feelings of fun and physical relaxation, and to the outcome of using leisure to entertain themselves and prevent boredom.

In the follow-up study, this meaning was expressed by several students. Tina, a primary education student, captured the experience by saying: 'To me leisure would be something you do in your spare time, to relax; I suppose relaxing and not doing anything, like going down the backyard talking to my pet chickens, you know you just muck around with them, it's fun.' When asked to clarify the meaning of spare time, Tina said: '[It's] the time when you don't have to be doing something; unoccupied time. I have a lot of spare time.' The meaning of relaxing was elaborated in terms of: 'probably just doing nothing; giving your body a bit of time off'; and then linked to spare time: 'You just sit there, it's not worthwhile, and you're not achieving anything, like you just waste time or in the holidays, you know, you need to fill time or you'll get bored.'

While some students in the follow-up study replicated most or all aspects of passing time, and indicated this was their only or dominant meaning, some students expressing other leisure meanings also experienced leisure as passing time. This was particularly so for students describing exercising choice, but to a lesser extent for students describing leisure as escaping pressure and who had little time for leisure, and for students who experienced leisure as achieving fulfilment and who failed to distinguish between blocks of discrete time in their lives. What was interesting about students who expressed more complex meanings and who referred to passing time, was their transcripts contained fewer aspects or a partial awareness of the experience. For instance, a discussion with Brenton, one of the second-year environmental science students, focused on leisure as exercising choice. However, he also referred to leisure as 'times between lectures where I have spare time between other things I do' and 'it's good to just have nothing important to do, you know, just spend time to shoot the breeze and hang out basically.' Brenton, however, didn't mention aspects such as physically relaxing or needing to be entertained and there was no sense of boredom. When asked to explain his experience, Brenton related spare time to choosing how he wanted to spend time. In other words, Brenton's reference to spare time and having nothing more important to do, which reflected the focus of passing time, was understood from the perspective of another experience - exercising choice.

Leisure as exercising choice (B) The initial meaning of exercising choice described leisure in terms of being free to choose to do what one wants to do. Aspects forming the experience related to the perception of obligations, want- 
ing greater control in life, having free time, feelings of emotional relaxation and enjoyment or satisfaction, and becoming a self-determined individual. Subtle differences in the values of aspects suggested two sub-categories of meaning with one experience emphasising being free of other people's expectations, and the second emphasising the desire to be free of responsibilities. In the follow-up study the same meaning and sub-categories were evident.

One of the humanities students, Sharon, described the first experience as 'going to my friend's place, I like playing guitar, um, listening to music, watching cricket.' When asked about what made these examples leisure, Sharon replied: 'You feel relaxed about yourself, um, you can talk about anything that you choose to talk about basically and not feel that your friends are judging you, ah just a state of comfort ... you can speak frankly about things that concern you, you're not on your guard' and 'I'm usually my real self when I don't have to live up to others' expectations and when I can say and do what I want.'

Students describing the second experience also emphasised the centrality of choice, but often focused on choosing activities that provided opportunities to display their competence as individuals. Adrian, a second-year student enrolled in a technical education course, described the experience thus: 'Re-building my car is leisure for me, like after I have done my study or after my other responsibilities. I like being able to strip the car to pieces, strip the paint off and start repairing dents, any modifications you want to.' When asked to clarify what made the activity leisure, he said: 'I guess the feelings of being able to do something that someone else hasn't done; you can do it how you want. It's always good to hear compliments from your mates when they see it's finally done, show off your skills a bit. It gives me immense enjoyment, like how to bend this car straight, um; it makes me feel satisfied and good about myself.'

From the initial study, the two variations of the experience were respectively labelled exercising choice: responding to others' expectation (B1) and exercising choice: responding to personal responsibilities (B2). This distinction was made according to how students related to the perception of obligations (i.e., as expectations or as responsibilities). While the distinction appears in Sharon's and Adrian's descriptions, follow-up interviews suggested a more critical difference in the form of a relation between feelings of personal insecurity and the need to assert control to become independent, or developing personal confidence through displaying one's competence as an individual. Some students reflected insecurity using phrases such as: 'I was constantly worrying about what I was going to do for a job,' 'I'm worried by what others think of me,' or 'it's important for me to be accepted for who I 
am.' Others referred to feeling confident through expressions such as: 'I don't worry about what others think because I know I'm good enough,' 'doing that gives me confidence in myself,' 'I like to challenge myself, to show myself that I'm capable of doing things,' and 'I feel satisfied with who I am.' In many cases, students referred to both sets of phrases which, along with references to 'being free', 'choosing what I want' and 'it's my decision about what I do,' maintained the two experiences as being variations of the same meaning.

The apparent tension between insecurity and confidence implied the meaning of exercising choice and the emphasis on freedom was related more to the need for personal acceptance and recognition than to how one perceived obligations. Although this tension may seem a minor semantic differentiation, it reinforces the idea that some students experienced leisure as a dialectic and emergent process of establishing their personal identities. Hal, one of the psychology/criminal justice students expressed this dialectic thus: 'Sometimes I feel uncertain about myself and feel the need to make a statement, but other times I know who I am and where I am going in life.' Subsequently, a more accurate description reflecting students' concerns about their need to become their own person, suggested re-labelling the experience as: exercising choice by asserting one's control (B1) and exercising choice to display one's competence (B2).

Leisure as escaping pressure (C) The initial description of escaping pressure described leisure as needing to escape the pressures of life by getting away, relaxing and rejuvenating oneself. The experience included the aspects of changing a stressful work or family situation, finding or making time for oneself, feelings of mental relaxation and pleasure, and restoring a sense of balance to help cope with the pressures of life.

Emerging from the follow-up study was a within-category distinction reminiscent of the dual experience apparent in leisure as exercising choice. Consequently, two variations of the escaping pressure experience can be reported: escaping pressure by forgetting about the problems of life $(\mathrm{Cl})$ and escaping pressure to understand the problems of life (C2). Although both versions share the same aspects forming the experience, they appear to arrive at different ways of relieving pressure and restoring balance.

The essential feature of the difference was that escaping pressure by forgetting life's problems emphasised changing a situation by removing oneself from the source of pressure to completely forget about or block out pressure. In contrast, escaping pressure to understand life's problems focused on changing a situation by removing oneself from the source of pressure in order to reflexively consider the situation causing pressure. However, unlike the 
case with exercising choice where many students expressed both versions of the experience (i.e., B1 and B2), students describing escaping pressure generally related to one of the experiences. The following interpretations and excerpts from interviews elaborate this distinction.

In the experience of escaping pressure by forgetting about the problems of life ( $\mathrm{Cl}$ ), leisure was related to the context of: (1) needing to manage frequent and high levels of pressure, (2) having no time or as little as a few minutes or hours for oneself, (3) often feeling guilty about one's personal situation or taking time for oneself to relax or doing something pleasurable, and (4) understanding leisure as a reward or compensation for dealing with pressure.

One student expressing this experience was Stephanie, a mature age teacher-education student. Married with two children, Stephanie, talked about feeling guilty when leaving her children in day care when she left to go to university: 'When you see them crying, when you walk away, I think I shouldn't be doing this and it's a kind of guilt.' She also mentioned a selfimposed form of pressure that came from 'expecting to be a positive role model' for the younger students with whom she studied at university. In this context, Stephanie recalled 'not having a lot of time,' and of understanding the experience to be 'a release away from university study when I can escape where I choose to spend time with my children and partner to compensate them by spending a little time and having leisure.'

In contrast, escaping pressure to understand the problems of life (C2) was situated in the context of: (1) needing to manage pressures associated with the demands and routine of daily life, (2) having access to relatively longer periods time for leisure such as half-days, week-ends or extended holidays, (3) perceiving the taking of time out for leisure as a right or necessity, and (4) consciously using leisure to reflect upon and understand the source of pressure.

Chris, a postgraduate research student, expressed his experience by saying that: 'I think leisure can be just sitting on top of a hill and changing your space ... the right to time for yourself to think about things [or] just watching the waves and birds and stuff. It mightn't sound like leisure, but that time to reflect, to think about yourself . . you sort of start coming to this point of harmony with yourself. You know you might have failed an exam or have pressures, but then once you sit down and realise that it's not the end of the bloody world; that's leisure.'

A question arising from the distinction in meaning is whether the two versions are the same experience or qualitatively different and should therefore be considered separate categories of meaning. Given the two experiences 
include the same aspects and share the same outcome of relieving pressure and restoring balance, the former proposition appears more tenable. Furthermore, informal inspection of the coding marks in interview transcripts supported the viability of the proposition given the propensity for transcripts coded as $\mathrm{Cl}$ to also have $\mathrm{B} 1$ marks, and conversely, transcripts coded as $\mathrm{C} 2$ to be more likely to include B2 marks and in some cases references to the most complex understanding, achieving fulfilment (D). That is, the $\mathrm{Cl}$ experience appeared to be a logical extension of Bl (e.g., personal insecurity leading to feeling guilty) and similarly, the C2 version to be an extension of B2 (e.g., developing confidence being related to sometimes needing to sort through problems to reinstate confidence).

Leisure as achieving fulfilment (D) In comparison to the focus on filling time, exercising freedom or restoring balance, achieving fulfilment emphasised the emotional condition of being happy and contented. From the initial study, aspects of the meaning were experienced as: finding opportunities for leisure in different areas of life; a sense of timelessness, flow and being absorbed in the moment at hand; deeply held feelings of spiritual connectedness or relaxation; actively contributing to other's happiness; and a developed perception of being a self-actualising person. Achieving fulfilment was a more difficult experience to comprehend and describe compared with other experiences. The explanation given for this was that being happy was independent of time and activity, different feelings contributed to happiness, and the experience had a strong ephemeral quality.

Some of the aspects of the experience in the follow-up study were recognisable in an interview with a performing arts student, Ruby, who first described leisure as escaping pressure to understand life's problems (C2). This meaning was expressed through bushwalking which Ruby saw as 'mentally relaxing, something which calms you down, gives you think time ... it's the whole thing of relaxation and escaping stress, it's making you positive rather than sort of mixed up and jumbled.' This example was followed towards the end of the interview with a description of playing the piano that was more illustrative of achieving fulfilment. Ruby observed: 'Music really does it for me because it's a very emotional thing and that makes me feel happy inside ... the sound's really nice and then that makes me feel emotional, it's a sort of meditation, focusing on something and putting your energy into it ... and it's involving and creative, can't think of the word, it gets your attention totally, absorbing and fulfilling.'

A feature of the achieving fulfilment experience more apparent in the follow-up study was the importance of aesthetic qualities associated with leisure. 
For example, Ruby extended her discussion about playing the piano by noting that 'it's the sensory stimulation, almost like going back to kind of a childlike thing where it's touch, smell and taste, it's a sort of simplicity.' Kate, who also studied performing arts, gave horse riding and living in her house as examples of leisure. When asked about what made horse riding leisure, Kate said: 'I love the fact that when I go horse riding there's such a sense of something being bigger than you, everything being bigger than you but connected to part of it all, yeah. Horses are such huge powerful creatures, just absorbing the smell of the air or you know the feel of the ground or the way the breeze is moving.' In describing being in her house as leisure, she remarked: 'I find my house, I love my house; it's sort of one of those places where I like the light and the way it smells and the way it looks. It has a nice feeling about it, just being there in the moment and feeling very happy with these things makes it leisure.'

Three observations are worth noting about the meanings derived from the follow-up study. First, despite the modification made to the exercising choice category, that is the identification of an additional sub-category described for escaping pressure and the emphasis on aesthetic awareness in achieving fulfilment, no additional meanings were found that met the criterion of being qualitatively different. This finding suggests the four initial meanings were a reasonably accurate set of categories for describing students' experiences of leisure. Second, while the meanings represent distinctly different forms of experience, variations or shades of how particular meanings were experienced became more evident. With reference to this observation, it appears as though the sub-categories may represent important transitional stages, perhaps acting for students as change points between previous and succeeding experiences. And third, change in experience where shifts occurred between different meanings highlighted how awareness of a particular meaning appears to be flavoured by the focus of a previously experienced meaning or in some cases, a succeeding meaning, perhaps grasped but not yet fully understood. In the quest to sharpen distinctions among meanings, their overlapping and dynamic qualities emerge as important features of students' experiences.

\section{Clarification of the dimensions of variation}

The follow-up study revealed a significant increase in the number of aspects in students' descriptions of leisure compared with the initial study. However, none were common across all four meanings or were sufficiently significant to indicate the need to include new dimensions. Most students' descriptions of leisure contained some overt or implied instances that referred to a context or situation in which they experienced leisure, a need or intention they were seeking to satisfy, reference to a temporal component, various feelings or 
emotional attributes, and a consequence or outcome of their engagement in activity. One dimension requiring modification, however, was the emotional dimension and inclusion of the aspect of freedom. Although this aspect was initially identified as being central to exercising choice, freedom was also evident in the follow-up study for other categories of meaning and generally associated with feelings of enjoyment or relaxation.

In passing time expressions of freedom were associated with references to spare time. For example, 'I had left over time, so I was free to spend it doing things that were fun' or 'after coming home from work and before I get dinner I'm free to choose how I fill that time.' One student captured her awareness of freedom by observing that 'because I'm older and have a car and money you have more freedom. When you're a child, you're basically restricted to an area, like a couple of streets or when you're out of school you can chose what you want.' The meaning of freedom in this experience appeared to be created by access to resources permitting greater freedom, and enforced by external agents in the form of rules imposed by parents, school hours or family needs. Consequently, the label of 'conditional freedom' was given to this experience to denote the highly prescribed or structured meaning of the aspect.

In contrast, freedom in exercising choice related to the idea of being free to be oneself, and was actively exerted by students' decision to have free time in which they could establish or make their own choices. Statements such as 'it's choosing your own friends', 'no one can tell me what to do, it's how I want it to be' or 'it's choosing what you can do and there are no consequences of your action', illustrated this meaning. Consistent references to the self in juxtaposition with others, and to an emergent sense of forging one's identity, suggested the meaning of this aspect was defined in terms of the 'freedom to be oneself'.

In escaping pressure, freedom was defined as being free from internally perceived sanctions (e.g., feeling guilty about taking time) or externally imposed constraints (e.g., stress from work or family life). Freedom was recognised by students as a pre-existing aspect, which had become lost or diminished in the presence of pressure and was something they were looking to re-establish. An environmental science student, Paul, said that after working long hours studying and doing his two part-time jobs, he just felt overwhelmed, you know when everything is caving in on you and you just think I will choose to take time out to get away from all those things that stress me.' For students like Paul, freedom in this experience denoted the meaning of being 'free from constraint'.

In achieving fulfilment, the experience of leisure conveyed an unconditional quality; of being free of all necessity. Free of necessity meant not being aware or concerned about time, one's identity, or internal and external 
constraints identified in the previous meanings. Peter extended the lack of conditions to include his own physical wellbeing when riding his motorbike. 'Sometimes I choose to take off my helmet, point the bike down the road and open the throttle full bore. The adrenalin, wind tugging at my body; I become my bike, speeding through time, it's pure raw feeling.' When asked to expand, Peter said: 'I don't know how else to describe it; I come away feeling alive, you know, I have really lived.' Subsequently, the phrase 'unconditional freedom' captured variations between this relational value and the values ascribed to freedom in other experiences of leisure.

\section{The distribution and differences in leisure meanings among students}

As noted previously, meanings and dimensions of leisure appear to be intercorrelated, both at the level of the individual student and at the collective level among categories. This feature makes it difficult to accurately and perhaps meaningfully describe the distribution of meanings. Nevertheless, by applying the decision rule of attaching individuals to a particular meaning reflecting their dominant and most complex understanding, some general features about the prevalence of meanings can be observed.

The frequency of meanings for the combined sample of leisure and nonleisure majors and for each separate major are reported in Table 1. Inspection of the table shows 9 students expressed passing time (16\%) as their most dominant leisure meaning, 29 as exercising choice (52\%), 13 as escaping pressure (23\%), and 5 as achieving fulfilment (9\%). The most frequent understanding of leisure was therefore experienced as exercising choice by 5 out of every 10 students, followed by escaping pressure and passing time. Achieving fulfilment was the least frequently experienced meaning with approximately 1 in every 10 students describing the meaning.

The major difference apparent between female and male students' leisure meanings was that more female students experienced leisure as exercising choice by asserting control (B1) and escaping pressure to forget about problems ( $\mathrm{Cl}$ ) compared with male students. Although the magnitude of difference is small and may be an artefact of the higher number of females in the sample compared with males (59\% and $41 \%$ respectively), females were somewhat more likely to express meanings associated with feelings of insecurity and guilt.

When the two groups of students were analysed separately, 6 leisure studies students experienced passing time (18\%) as their most dominant leisure meaning, 17 as exercising choice (52\%), 7 as escaping pressure (21\%), and 3 as achieving fulfilment (9\%). For the non-leisure studies students, 3 referred to leisure as passing time (13\%), 12 to exercising choice (52\%), 6 to escaping 
Table 1. Distribution of leisure meanings by student characteristics

\begin{tabular}{|c|c|c|c|}
\hline $\begin{array}{l}\text { Student } \\
\text { Demographics }\end{array}$ & $\begin{array}{l}\text { Combined } \\
\text { Sample }(n=56)\end{array}$ & $\begin{array}{l}\text { Leisure Studies } \\
\text { Students }(n=33)\end{array}$ & $\begin{array}{l}\text { Non-leisure } \\
\text { Students }(n=23)\end{array}$ \\
\hline \multicolumn{4}{|l|}{ Passing Time (A) } \\
\hline Mean age/range & $17.8, r=17.0-19.5$ & $17.8, r=17.0-19.5$ & $17.7, r=17.1-18.2$ \\
\hline Gender & $4 \mathrm{~F} / 5 \mathrm{M}$ & $2 \mathrm{~F} / 4 \mathrm{M}$ & $2 \mathrm{~F} / 1 \mathrm{M}$ \\
\hline Entry mode & 9SL/OMA & 6SL/0MA & 3SL/0MA \\
\hline \multicolumn{4}{|c|}{ Exercising Choice by Asserting Control (B1) } \\
\hline Mean age/range & $18.9, r=17.1-21.3$ & $18.8, r=18.5-19.5$ & $19.0, r=17.1-21.3$ \\
\hline Gender & $9 \mathrm{~F} / 5 \mathrm{M}$ & $7 F / 3 M$ & $2 \mathrm{~F} / 2 \mathrm{M}$ \\
\hline Entry mode & $12 \mathrm{SL} / 2 \mathrm{MA}$ & 9SL/1MA & $3 S L / 1 M A$ \\
\hline \multicolumn{4}{|c|}{ Exercising Choice to Display One's Competence (B2) } \\
\hline Mean age/range & $22.0, r=18.1-26.8$ & $20.9, r=18.1-26.5$ & $23.0, r=19.0-26.8$ \\
\hline Gender & $9 \mathrm{~F} / 6 \mathrm{M}$ & $4 \mathrm{~F} / 3 \mathrm{M}$ & $5 \mathrm{~F} / 3 \mathrm{M}$ \\
\hline Entry mode & 8SL/7MA & $5 \mathrm{SL} / 2 \mathrm{MA}$ & $3 \mathrm{SL} / 5 \mathrm{MA}$ \\
\hline \multicolumn{4}{|c|}{ Escaping Pressure by Forgetting Problems of Life (C1) } \\
\hline Mean age/range & $21.9, r=19.7-26.3$ & $21.3, r=19.7-23.2$ & $22.5, r=20.1-26.3$ \\
\hline Gender & $6 \mathrm{~F} / 3 \mathrm{M}$ & $3 \mathrm{~F} / 2 \mathrm{M}$ & $3 \mathrm{~F} / 1 \mathrm{M}$ \\
\hline Entry mode & 2SL/7MA & OSL/5MA & $2 \mathrm{SL} / 2 \mathrm{MA}$ \\
\hline \multicolumn{4}{|c|}{ Escaping Pressure to Understand Problems of Life (C2) } \\
\hline Mean age/range & $26.5, r=18.2-40.2$ & $25.0, r=23.0-26.9$ & $29.0, r=18.2-40.2$ \\
\hline Gender & $3 \mathrm{~F} / 1 \mathrm{M}$ & $1 \mathrm{~F} / 1 \mathrm{M}$ & $2 \mathrm{~F} / 0 \mathrm{M}$ \\
\hline Entry mode & $1 \mathrm{SL} / 4 \mathrm{MA}$ & OSL/2MA & 1SL/1MA \\
\hline \multicolumn{4}{|c|}{ Achieving Fulfilment (D) } \\
\hline Mean age/range & $28.4, r=23.1-38.0$ & $30.7, r=25.2-38.0$ & $26.0,23.1-29.0$ \\
\hline Gender & $2 \mathrm{~F} / 3 \mathrm{M}$ & $1 \mathrm{~F} / 2 \mathrm{M}$ & $1 \mathrm{~F} / 1 \mathrm{M}$ \\
\hline Entry mode & 0SL/5MA & OSL/3MA & $0 \mathrm{SL} / 2 \mathrm{MA}$ \\
\hline
\end{tabular}

pressure (26\%), and 2 to achieving fulfilment (9\%). While noting similarity between the groups in regard to the percentage of students expressing exercising choice and the smaller number describing achieving fulfilment, the most notable difference lay in the larger percentage of leisure studies students expressing passing time and the higher percentage of non-leisure studies students expressing escaping pressure. 
Apart from this numerical difference, informal inspection of interviews showed about a third of leisure studies students used linguistic terms reflecting textbook definitions of leisure. These terms were almost solely evident in the second-year interviews after students had received two years of instruction in leisure theory and practice courses. Two commonly used definitions were the state of mind conception emphasising free choice which approximated the exercising choice meaning and the flow definition which appeared as one aspect in achieving fulfilment. In the first round of interviews conducted before students began their studies these terms were absent, and most interesting, by the third and final interviews, use of textbook definitions had almost completely disappeared from student descriptions. Other than not using textbook definitions, perhaps the most distinguishing feature about non-leisure studies students' descriptions of leisure was a broader variety of examples used to describe leisure and fewer references to active forms of leisure such as sport. Despite these differences, Weissinger et al.'s (1992) caution about biases resulting from using leisure studies students does not appear to be problematic in the context of the present study given both groups of students had the same or similar leisure meanings.

\section{Support for the proposed order of development in understanding leisure meanings}

Demographic characteristics of students combined with narrative information about their life experiences provided the basis for profiling students contributing to each category of meaning and corroborating the development in meaning reported in the initial study. As seen in Table 1, leisure studies and non-leisure studies students classified as experiencing leisure as passing time were the youngest age group with a mean of 17.8 years $(r=17.0-19.5)$. All entered their respective academic programs straight from high school and most lived with their parents or were being supported by them (e.g., through living away from home allowances). While most students identified relatively passive forms of leisure, others participated in local or state level sporting competitions requiring regular training commitments. Interviews typically communicated the idea of uncomplicated and easy lifestyles with large blocks of discretionary time and few work or domestic duties. One recurring concern for these students was how to fit full-time study or training priorities around their hectic social lives.

In comparison, students contributing to both versions of exercising choice were nearly three years older ( $M=20.7$ years) than students contributing to passing time. Analysis of the two sub-categories showed students experiencing leisure as exercising choice by asserting control (B1) had an average age 
of 18.9 years (range, 17.1-21.3). Twelve of these students were school leavers and 2 mature age entrants. While many lived at home, some lived in privately rented or student accommodation and most held part-time retail and hospitality jobs suggesting a higher level of independence compared with students in passing time. Of particular note was the large number of females in the group and the frequency with which they talked about anxieties relating to relationships with parents, siblings, friends, or partners, their academic performance or future employment prospects. Overall, interviews with this group were marked by a concern for developing interpersonal relationships.

Similar life experiences were reported by students describing leisure as exercising choice to display one's competence (B2). This group had an average age of 22.0 years (range=18.1-26.8). Eight entered university as school leavers and 7 as mature age entrants. Some lived with their parents, others in student accommodation, and a few in their privately rented housing. Students exhibited a wider range of interests compared with students in passing time and the Bl category, although they similarly emphasised the importance of their social lives. Forms of leisure that challenged their physical or social skills were more frequently described in their interviews. A few had travelled interstate or internationally for holidays, some were gaining volunteer work experience, and others had regular part-time paid work. Work experience was often linked to students' fields of academic study and appeared to provide them with a sense of confidence in their abilities and direction in life. However, on occasions, these students expressed insecurities similar to the previous group, although such insecurities were balanced against or superseded by more frequently expressed needs to display their identity.

Students describing leisure as escaping pressure were generally older $(\mathrm{M}=23.5$ years $)$ than students in previous categories. In the escaping pressure by forgetting about life's problems $(\mathrm{Cl})$ sub-category, students were around five years younger than those describing escaping pressure to understand life's problems $(\mathrm{M}=21.9$ years, range $=19.7-26.3$ years, compared with a mean of 26.5 years and range $=18.2-40.2$ years). In both sub-categories, most students were mature age entrants, lived in their own homes, worked part- or full-time in a variety of service or trade occupations, and had returned to university study after a period of leave. While their lives were characterised by a greater sense of control compared with students in exercising choice, life was complicated by work demands, domestic duties (e.g., caring for disabled siblings, ageing parents, their own or others' children), increased financial commitments (e.g., study costs, mortgage payments) and significant reductions in personal time. Interpersonal sources of pressure from difficult or abusive relationships with parents or partners, negotiating gender stereotypes, 
and dealing with racial prejudice as Aboriginal Australians or learning new cultural contexts were also noted.

Apart from the age difference between sub-categories, students describing escaping pressure by forgetting life's problems $(\mathrm{Cl})$ reported higher levels of stress and seemed to live more chaotic lives compared with those relating to escaping pressure to understand life's problems (C2). Moreover, some of the former students said they could not actually escape life's problems or could only achieve a temporary respite through leisure, whereas the latter students were more likely to note lasting feelings of rejuvenation and mental composure as a consequence of leisure.

Of the five students describing leisure as achieving fulfilment, all were mature age entrants with an average age of 28.4 years (range $=23.1-38.0$ years). This was the oldest group of students and displayed the widest range of life experiences. Full-time work in middle management or similar positions of responsibility in government or business organisations, long-term marital or de facto partnerships with or without children, major forms of illness or death among family or friends, interstate or international migration, and extended periods of solo travel, were described by these students. Conveyed through their experiences were various references to empathy and altruism, high levels of aesthetic awareness, playful spontaneous forms of physical and social risk taking, contemplative non-judgemental or critically informed philosophical orientations, cosmopolitan perspectives balanced against an appreciation for one's local community or home country, and acknowledgement of their mortality. To the extent these qualities were consistent with emotionally intelligent, self-actualising individuals, students' descriptions of leisure and life were intertwined in a way suggesting a level of personal maturity beyond that exhibited by students contributing to other meanings.

When taken together, the findings demonstrate positive relationships among meanings and students' characteristics. These relationships show age and life experience increase with progression from passing time, to exercising choice, to escaping pressure, to achieving fulfilment. The same relationships were evident when a finer level of analysis was applied to the characteristics of students contributing to the sub-categories of exercising choice and escaping pressure.

Positive relationships among meanings and student characteristics do not demonstrate that younger students with fewer life experiences have less complex understandings of leisure, older and experienced students have more complex understandings, or students of different ages cannot experience less or more complex leisure meanings. However, the direction of the relationship among meanings and student characteristics corresponds with the direction 
of the relationship among meanings and the growth in complexity of understanding leisure interpreted from the initial study. This finding therefore supports the proposed order of complexity in understanding from passing time to exercising choice to escaping pressure to achieving fulfilment, and adds further weight to the contention that meanings reflect students' developmental capabilities for describing their experiences as leisure. The likely path of development in leisure meanings, extended to include apparent developmental differences among the sub-categories of exercising choice and escaping pressure, is summarised in Figure 1.

Figure 1: Proposed order of development in understanding leisure

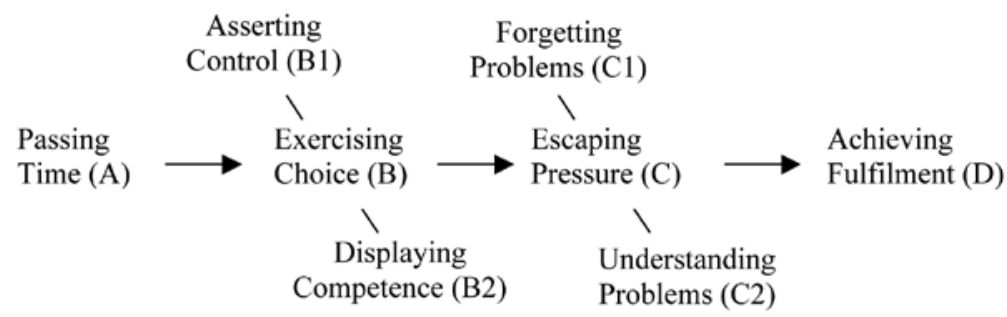

Less complex understandings

More complex understandings

\section{Conclusions}

This study investigated whether results derived from an initial study of leisure meanings would be supported by additional interviews conducted with the same leisure studies students and a sample of non-leisure studies students. Bearing in mind the use of a study design that sought to clarify a previous set of results through iteration and cumulative understanding, several conclusions can be drawn in relation to the research questions. (1) The four meanings and dimensions of variation appear to represent a reasonably accurate set of tools for describing students' different ways of experiencing leisure. (2) Leisure studies and non-leisure studies students share similar leisure meanings in terms of the content of their experiences. (3) Positive relationships among meanings and student characteristics when combined with knowledge about complexity in understanding leisure support the argument for leisure meanings being developmentally ordered. Collectively, these results provide a more sharply defined set of meanings and dimensions, and suggest a more exact ordering of meanings from which change in students' experiences of leisure can be explored. 


\section{References}

Denzin, N. (1978). Sociological methods (2nd ed). New York: McGraw Hill.

Henderson, K., Bialeschki, D., Shaw, S., \& Freysinger, V. (1999). Both gains and gaps: Feministic perspectives on women's leisure. State College, PA: Venture.

Hoffer, B., \& Pintrich, P. (1997). The development of epistemological theories: Beliefs about knowledge and knowing and their relation to learning. Review of Educational Research, 67(1), 88-140.

Kleiber, D. (1999). Leisure, experience and human development: A dialectical interpretation. New York: Basic Books.

Marton, F. (1986). Phenomenography: A research approach to investigating different understandings of reality. Journal of Thought, 21(3), 28-49.

Marton, F., \& Booth, S. (1997). Learning and awareness. New Jersey: Erlbaum Publishing.

Marton, F., Dall'Alba, G., \& Beaty, E. (1993). Conceptions of learning. International Journal of Educational Research, 19(3), 277-300.

Osgood, N., \& Howe, C. (1984). Psychological aspects of leisure: A life cycle developmental perspective. Society and Leisure, 17(1), 175-195.

Schulz, J., \& Watkins, M. (2007). The development of the leisure meanings inventory. Journal of Leisure Research, 39(3), 477-497.

Watkins, M. (2000). Ways of learning about leisure meanings. Leisure Sciences, 22, 93-107.

Watkins, M., \& Bond, C. (2007). Ways of experiencing leisure. Leisure Sciences, 29(3) 287-307.

Weissinger, E., Caldwell, L., \& Mobily, K. (1992). Use of recreation majors as research subjects: Differences between majors and non majors on leisure-related variables. Leisure Sciences, 14, 327-35. 